\title{
Rice BlastBiology and Reaction of Host to the Disease
}

\author{
Zelalem Zewdu \\ Ethiopian Institute of Agricultural Research, Fogera National Rice Research and Training Center, \\ P.O.Box 1937, Bahir Dar, Ethiopia
}

\begin{abstract}
Rice blast (Magnaporthe grisea) is first reported in China and then in Africa in1922. The disease is now the most widespread and devastating rice disease in all rice producing areas of the world. The disease can cause from mild yield reduction to total crop loss as depends on the variety and severity level.The rice blast isolate is closely related to the isolate of other blast like fungus and distinctly described as Magnaporthe grisea. Rice blast fungus starts the infection cycle after a three-celled conidium lands on the rice leaf surface. Thousands of spores can be produced from a single lesion within 15 days after infection. Symptoms on leaves start as small brown necrotic lesions that evolve to larger elliptical or spindle-shaped lesions, colored whitish to gray with darker borders while infected seeds display brown spots, which may result from the infection of the florets as they matured into seeds.The rice blast needs at least a 12-hour period of moderate temperatures $\left(25\right.$ to $\left.30{ }^{\circ} \mathrm{C}\right)$, high relative humidity (90-92\%), and high moisture which are conducive for its development.The disease can be managed by using resistant varieties, using integrated disease management options and nutrient managements like application of recommended nitrogen fertilizers and application of silicon fertilizers. The rice plant respond differently for reducing the occurrence and damage of the disease either fungus is incapable causing sporulating lesions on the plant or the plant develop residual resistance that remains when complete resistance has been overcome by the pathogen.
\end{abstract}

Keywords: Rice, Blast, Magnaporthe grisea, Host Reaction

DOI: $10.7176 / \mathrm{JBAH} / 11-18-02$

Publication date:September $30^{\text {th }} 2021$

\section{Introduction}

Rice blast is reported for the first time in China in 1637 (Dounia, 2013) and considered as center of origin and diversity of rice blast fungus, Magnaportheoryzae. It was first reported in Africa in 1922, and is now the most widespread rice disease in more than 85 countries of the world (Jia et al., 2009). According to Wassmann et al. (2009), rice blast occurs in a wide range of climatic conditions, from temperate to tropical. The pathogen is disseminated by wind, infected plant debris or seeds left in the fields. Preethi, (2005) noted that this disease has various names, including rice blast fungus, rice rotten neck, rice seedling blight, blast of rice, oval leaf spot of graminea, pitting disease, ryegrass blast, and Johnson spot. Several rice blast epidemics that have occurred worldwide have resulted in losses ranging from 40 to $75 \%$ yield loss in (Kayeke et al., 2011); reaches up to $100 \%$ in commonly grown commercial rice varieties under Ugandan condition (Chuwaet al., 2015).

Typically, yield losses due to blast range from $1-50 \%$ in different rice-growing regions of the world, influenced by the type of cultivars grown and the prevailing environmental conditions (Hajano et al., 2011). However, under conditions favorable to the disease, losses may reach up to $90 \%$ (Lule et al., 2014). In Southern and South East Asia the losses due to blast were estimated to be about US \$55 million annually (Preethi, 2005).

Blast is the most widespread disease of rice in SSA. A survey conducted in farmer's field in Burkina Faso showed that farmers' tried to intensify rice cultivation with use of fertilizer however, increased yield losses have been realized because the recently released varieties are susceptible to blast (Séré et al., 2005). Yield losses of up to $22 \%$ were recorded in rain-fed lowlands, up to $45 \%$ in irrigated systems in the south and west of the country, and up to $44 \%$ (equivalent to $2 \mathrm{t} / \mathrm{ha}$ ) in the irrigated areas in Kou (Séré et al., 2013). Yield losses up to $100 \%$ were reported by farmers in Ghana, and of over $80 \%$ in some locations in the Gambia and in Sierra Leone, for susceptible cultivars and accessions in experimental plots (Séré et al., 2013).

\section{Literature Review}

\subsection{Taxonomy of rice blast pathogen}

Rice blast pathogen belongs to the kingdom, fungi; phylum, Ascomycota; class, Sordariomycetes; order, IncertaeSedis; family, Magnaporthaceae; genus, Magnaporthe(Bussaban et al., 2005). Based on recent phylogenetic, molecular and morphological data, isolates of the fungus from rice and closely related isolates from other grasses like Eragrostriscurvula, Elusine coracana Lolium perenne, and Setaria spp. are taxonomically described as Pyriculariaoryzae, while isolates from Digitariasanguinalis (crab grass) are distinct and described as Magnaporthe grisea(David et al., 2012). 


\subsection{Disease cycle and epidemiology of rice blast}

The most common symptoms in commercial rice fields induced by $M$. oryzae can be found on all the above ground parts of the rice plant at all growth stages as indicated in Figure 2. The fungus uses a hemibiotrophic infection strategy that involves initial proliferation inside living host cells before switching to a destructive necrotrophic mode (Wang et al., 2014). The infection of rice by M. oryzae follows a developmental process that has been observed in many foliar fungal pathogens (Agrios, 2005).

Rice blast fungus starts the infection cycle after a three-celled conidium lands on the rice leaf surface as described by in Figure 1. The spore attaches to the hydrophobic cuticles and germinate, producing a narrow germ tube (Koga and Nakayachi, 2004; Richard et al., 2009). The germ tube produced from the conidium differentiates into a specialized infectious structure called the aspersorium, which adheres tightly to the plant surface using mucilage (Park et al., 2009). The fungus generates enormous turgor pressure inside the melanized aspersorium and a thin penetration peg pierces the host surface, using this pressure to enter a leaf epidermal cell. After penetration, the peg differentiates into bulbous and lobed infectious hyphae that grow intracellularly and intercellularly and result in blast lesions (Kato, 2001;Hirsch et al., 2008).

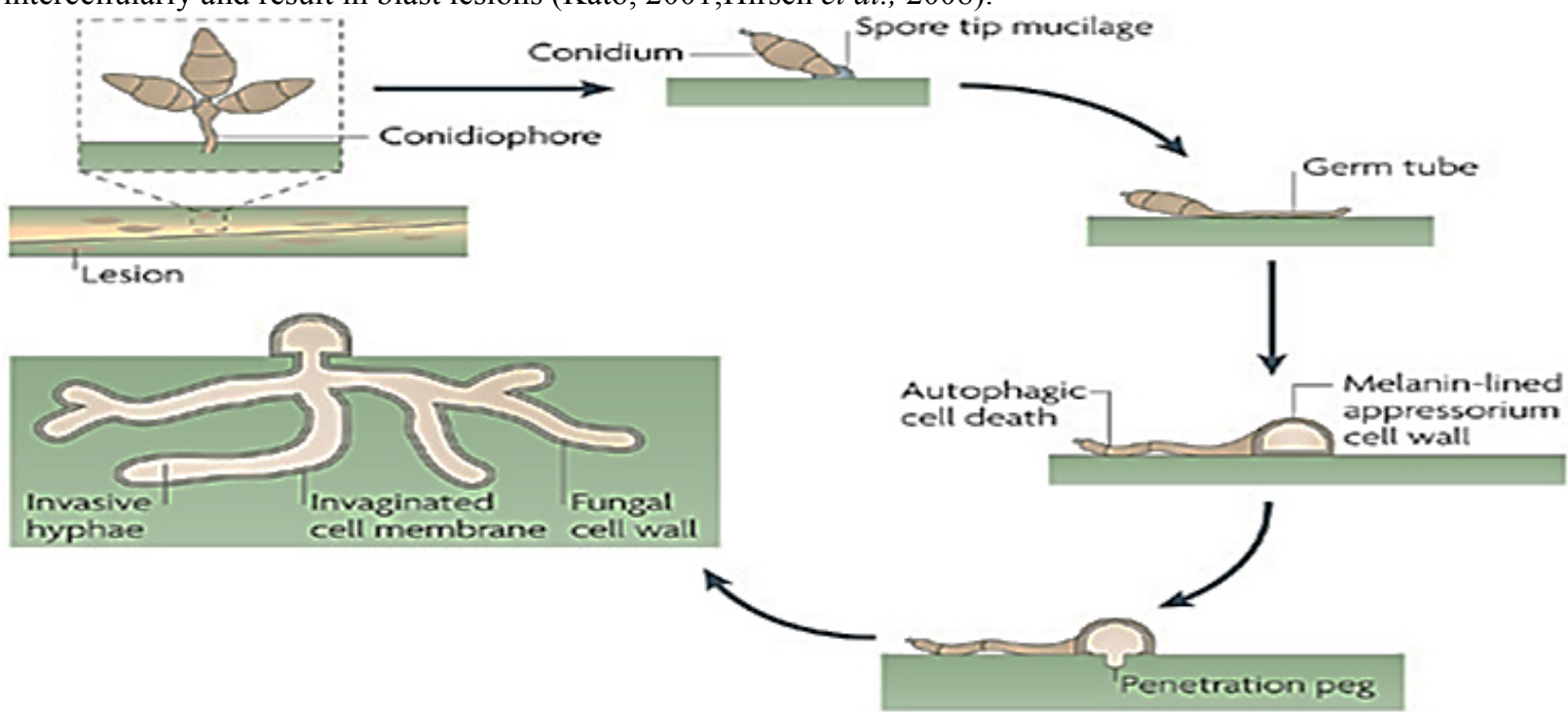

Source (Richard et al., 2009)

Figure 1: Disease life cycle of rice blast

Symptoms on leaves start as small brown necrotic lesions that evolve to larger elliptical or spindle-shaped lesions, colored whitish to gray with darker borders. On leaf margins, especially on the flag leaf ligule area, encircling lesions can cause the leaf to fall. Under favorable conditions, the lesions may enlarge and coalesce to kill the entire leaf and sometimes even the plant, under severe conditions, (Hirsch et al., 2008). Infected seeds display brown spots, which may result from the infection of the florets as they matured into seeds. Infected roots have also been observed, though lesions on the sheaths are relatively rare. Infection of young seedlings is initiated when the conidia are deposited on the leaf surface. The spores require water to germinate and attach to the leaf surface (Talbot, 2003).

Under optimal conditions, spore germination occurs rapidly, with polarized germ tubes formed within hours after landing on the leaf. Secondary cycles may be initiated by spores produced by lesions on the young seedlings. This process may be repeated many times through the growing season. Thousands of spores can be produced from a single lesion within 15 days after infection (Wang et al., 2014). According to Wang et al. (2014), typical blast lesions are diamond shaped, the first appearing dark green or grey with brown borders, while older lesions are light tan with necrotic borders. Under conditions favorable to the disease, lesions can merge together and rapidly enlarge to several centimeters in length, eventually killing the leaf and even the plant. On resistant cultivars, lesions induced by $M$. oryzae usually remain small $(1-2 \mathrm{~mm})$ and brown to dark brown (Wang et al., 2014).

The severity of rice blast and the number of spores produced on a single lesion depends on temperature, field conditions, relative humidity, fertilization levels, and genotype of the cultivar. In general, at least a 12-hour period of moderate temperatures $\left(25\right.$ to $\left.30{ }^{\circ} \mathrm{C}\right)$, high relative humidity $(90-92 \%)$, and high moisture are advantageous for rice blast development (Park et al., 2009; Yang et al., 2011). The severity of the disease during the vegetative phase highly influences the degree of disease during the reproductive phase. Spores produced at the end of the growing season may result in collar blast and neck blast as presented in Figure 2. Infection on the neck is generally considered the most deleterious phase of the disease because infection at this location can reduce seed set on the entire panicle (David et al., 2012). 


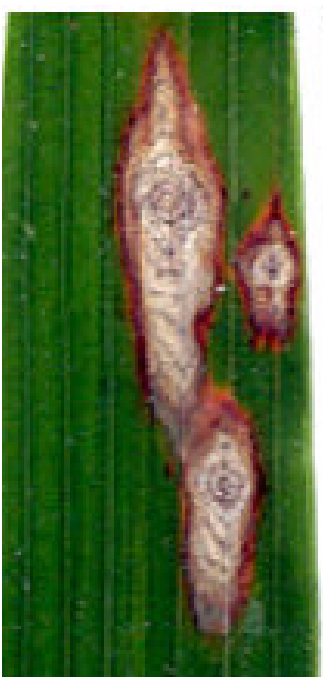

Leaf blast

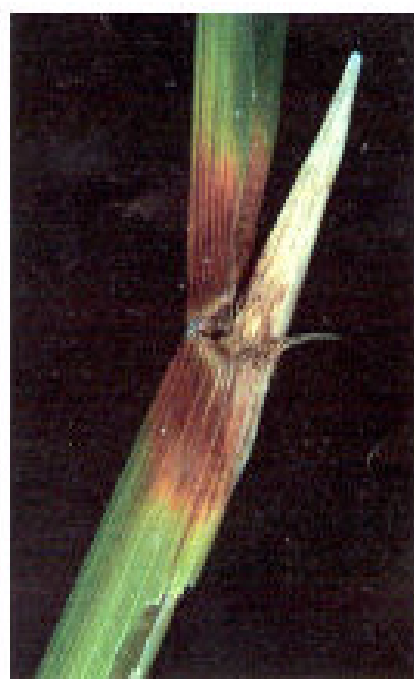

Collar blast

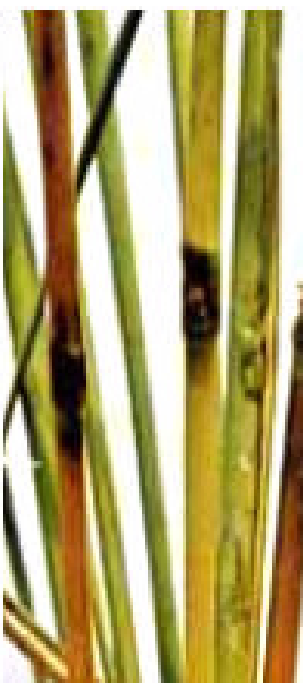

Node blast

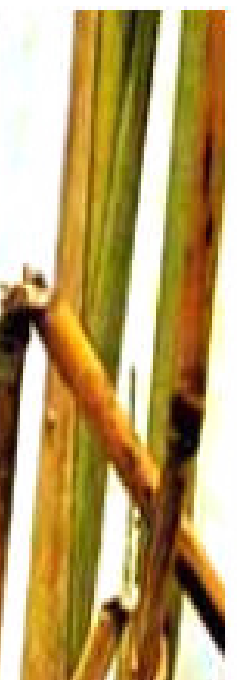

Neck blast

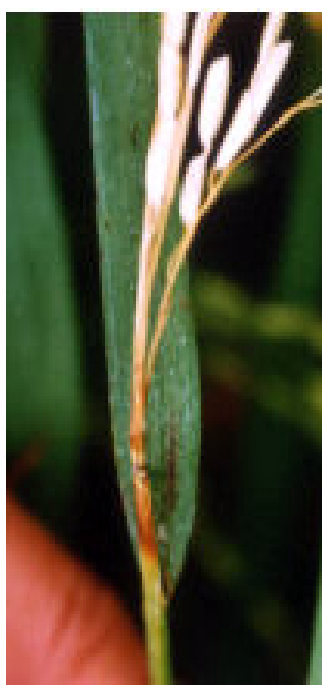

Figure 2: Development of blast symptoms on different above ground parts of rice plant

\subsection{Pathogen biology}

The fungus that causes rice blast is called Magnaportheoryzae (formerly called Pyriculariaoryzae). It is an ascomycete because it produces sexual spores (ascospores) in structures called asci, and is classified in the newly erected family Magnaporthaceae. The asci are found with in specialized structures called perithecia. The mycelium of M.oryzae is septate and the nuclei within the mycelium and spores of this fungus are haploid (Mekwatanakarn et al., 1999; David et al., 2012).

\subsection{Sexual reproduction}

The sexual, or teleomorphic, stage of the rice blast pathogen can be produced in the laboratory if isolates of opposite mating type are paired, but has not been found in field. As an ascomycete, it produces hyaline, fusiform shaped (spindle shaped with tapering ends) ascospores with three septa. This fungus is considered to be heterothallic with a bipolar mating system (mating controlled by two different alleles at a single locus) with additional genes controlling the sexual cycle (Mekwatanakarn et al., 1999; David et al., 2012).

\subsection{Asexual reproduction}

The asexual stage of Magnaportheoryzae is described by the name Pyriculariaoryzae (formerly called P. grisea) and it is the most common spore form of the fungus. These spores, called conidia, are produced abundantly on lesions and in culture on specialized stalks, called conidiophores. The conidia are usually three-celled, and produced on the apex of a conidiophore (David et al., 2012; Agrios, 2005).

Under favorable conditions, the fungus sporulates in the center of the lesions on susceptible cultivars, as well as on seed lesions. But the fungus sporulates rarely on the most resistant cultivars. Conidiophores and spores may give the lesions a dusty gray appearance, with spores being produced on the infected leaf, collar, panicle, and seed on conidiophores that extend beyond lesion surfaces (Park et al., 2009). Conidia, produced after several hours of high humidity, are easily released or liberated near mid-day, especially under windy conditions (David et al., 2012; Park et al., 2009).

\subsection{Rice blast management}

Developing resistant cultivars is the most desirable means of managing blast, particularly for small scale farmers. According to Balasubramanian et al. (2007); Kayeke et al. (2011) and Séré et al. (2013) different blast management practices found effective and utilized in the fields can be broadly classified as cultural, chemical, host resistance, or biological control. Generally, integrated disease management options are the best way to combat rice blast. Cultural practices like nutrient management, water management and time of planting have a large effect on managing rice blast (Kayeke et al., 2011). In addition to using resistant varieties, there are several factors that influence the development of rice blast disease. Two nutrients, nitrogen and silicon, significantly affect the disease occurrence and development. Studies have shown that high $\mathrm{N}$ supply always induces a heavy incidence of rice blast (Hori, 1898; Kayeke et al., 2011).

Delayed or large amounts of top dressings of nitrogen fertilizers are often responsible for severe disease. Plants receiving large amounts of $\mathrm{N}$ are found to have fewer silicated epidermal cells and thus lower resistance. On the other side, plants with a high silica content or a large number of silicated epidermal cells showed less 
damage from blast disease (Muriithiet al., 2005; Kayeke et al., 2011; Pooja \& Katoch, 2014).

Water availability affects the host plant's susceptibility to M. oryzae. Since rice grown in upland conditions (where the aggravating factor of drought stress is more common) is more susceptible than rice grown in flooded soil, flooding the field in upland rice may reduce the severity of blast (Nutsugah et al., 2008). Planting time also has a marked effect on the development of blast, with early planting being recommended. In tropical upland rice, crops sown early during the rainy season generally have a higher probability of escaping blast infection than latesown crops, which are often severely affected (Prabhu and Morais, 1986).

Among chemical control methods, many systemic fungicides with varying modes of action were useful for rice blast control, including anti-mitotic compounds, melanin inhibitors and ergosterol biosynthesis inhibitor (EBI) ( Iwata, 2001; Pooja and Katoch, 2014). In a chemical scheduling trial, Bavistin 1g/L spray at tillering + Hinosan $1 \mathrm{~g} / \mathrm{L}$ at heading and after flowering provided the best yield increase (Pooja and Katoch, 2014). Tricyclazole and Pyroquilon fungicides as seed dressers have been effective protection for up to eight weeks after sowing (Pooja and Katoch, 2014).

In field evaluation of commercial fungicidal formulations, Rabicide (tetrachlorophthalide), Nativo (tebuconazole + trifloxystobin) and Score (difenoconazole) were found to be most effective (Usman et al., 2009). Because of the development of resistance in the pathogen, site-specific fungicides are recommended to be used in mixture or in rotation. The non-fungicidal agents are supposedly specific to the target organism and less likely to lead to resistance problems (Yamaguchi, 2004). In addition to this, biological control using streptomyces sindeneusis sprayed on seedling leaves in Screenhouse had shown a strong inhibition of the pathogen and suppression of leaf symptoms (Zarandi et al., 2009).

\subsection{Breeding for resistance to rice blast}

Breeding for resistance is essential especially when chemical control is very expensive and impractical (Miah $e t$ al., 2013). In breeding for any target constraint, efficient selection approach is required. For rice blast disease, selection for major gene resistance in segregating population has been achieved by application of higher concentration of specific isolate at seedling stage (Trinh et al., 2008). The approach however, is inadequate for breeding for horizontal resistance, under polygenic gene action due to the relatively small difference in the resistance levels exhibited on using a spectrum of isolates.

During interactions between rice and blast pathogens, products of the R-gene can specifically recognize the corresponding elicitors of M. oryzae. After the discovery of Pia gene, by Kiyosawa, (1967) as the first blast $\mathrm{R}$ gene from the japonica variety Aichi Asahi, 99 blast $\mathrm{R}$ genes have been identified (Jin et al., 2010). From these $45 \%$ were found in japonica cultivars, $51 \%$ in indica cultivars, and the rest $4 \%$ in wild rice species (Wang et al., 2014). According to the Wang et al. (2014) report most deployed R genes have often been identified in Asian cultivated rice, with the exception of Pi9, Pi54rh, Pi40(t), and PirF2-1(t), which were domesticated from $O$. minuta, O.rhizomatis, O. australiensis, and O. rufipogon, respectively.

\subsection{Mechanism of resistance to blast disease}

Plants have different defense mechanisms against pathogens. These defense responses include a rapid, localized cell death termed the hypersensitive response, production of anti-microbial compounds, lignin formation, an oxidative burst and increased expression of genes related to pathogenesis (Stachowicz and Withlatch, 2005). Early studies on host resistance concentrated more on the nature of resistance. Miyake and Ikeda (1932), reported that the resistant variety Bozu, contains a larger amount of silicon than other the susceptible varieties.

Earlier studies showed that the degree of resistance increases in proportion to the amount of silica applied as well as to the amount of silicon accumulated in the plant. Yang et al. (2013), found that resistance to mechanical puncture of the leaf epidermis was positively related with resistance to blast. They found that puncture resistance was reduced by application of nitrogen fertilizer and by low soil moisture, but was increased as the plant became older. The distribution of starch in the leaf sheath is related to resistance in which the longer accumulation indicates more resistance. The resistance to penetration of the fungus is obviously less important than resistance to its spread within the host plant after penetration (Jia et al., 2000). In addition to this, Lavanya and Gnanamanickam (2000), found that rice plants resist the development of the blast disease through different mechanisms as smaller leaf area, narrowed leaf angle, fewer stomata, dwarf plants with better conversion efficiency of photosynthates from source to sink, thick epidermis and cuticle on leaf and neck, higher total phenols, and lower quantities of total and reducing sugars.

\subsection{Complete resistance}

Complete resistance to blast occurs when the fungus is incapable causing sporulating lesions on the plant. It is also known as specific resistance or true resistance (Séré et al., 2011; Pooja and Katoch, 2014). When a disease is controlled by a single gene (either dominant, recessive, nuclear or cytoplasmic), it is called monogenic resistance and is directly transferable from one variety to another through plant breeding methods (Mohapatra et 
al., 2008; Adams et al., 2000). Resistance to M. oryzae is a classical gene-for-gene system, where a major resistance gene is effective against pathogen strains possessing the corresponding avirulence gene (Rajashekara et al., 2014). But in the case of rice blast, success is short-lived or not easily achieved because of the presence of different physiologic races that overcome host resistance. In Korea, the resistance of the Tongil rice varieties was effective for 5 years before a virulent race of the pathogen appeared (Lee et al., 1976).

\subsection{Partial resistance}

Plants develop residual resistance that remains when complete resistance has been overcome by the pathogen. This type of resistance is referred to variously as horizontal resistance, general resistance, field resistance, or slow-blasting resistance (Miah et al., 2013). Varieties that have horizontal resistance become diseased when the environmental conditions are conducive to disease development. Horizontal resistance is desirable in varietal development because, with a greater number of genes contributing to resistance and the pathogen cannot mutate sufficiently to overcome all of them (Sattari et al., 2014; Plank, 1975).

Selecting for horizontal resistance is done in much the same way as selecting for higher yields. When the breeder selects plants or lines with lower levels of disease severity continuously over several seasons, the level of horizontal resistance will increase fairly. Horizontal resistance is not visible when such an effective major gene is present. The use of local material reduces the frequency of such non-durable still-effective major genes, as the local varietal population has adapted to these pathogens (Bonman, 1992; Pooja and Katoch, 2014).

According to Sattari et al.(2014), horizontal resistance affects the development of rice blast disease by reducing the number of spores required to cause infection, the latent period of the pathogen in the host, the number of lesions produced per unit of spores, the size of lesions, the lesion expansion rate, and the number of spores produced per lesion. Identification of slow-blasting segregants in segregating populations is difficult, particularly in bulk breeding systems. It might be somewhat easier in a pedigree system of breeding, where discrete progeny rows can be evaluated for identification of lines with slow blasting components.

\subsection{Mode of inheritance of blast resistance in rice}

The mode of inheritance of blast resistance in rice has been extensively studied by several scientists, who have indicated variously that resistance is conferred by monogenic dominant genes (Kumbhar et al., 2013), monogenic recessive genes (Rath and Padmanabhan, 1972), two dominant independent genes (Padmavathi et al., 2005), two dominant complementary genes (Padmanabhan, 1975), two recessive duplicate genes (Rath and Padmanabhan,1976), or minor genes in the parents (Roumen, 1993).

According to Padmavathi et al. (2005),blast resistance genes were found on 30 different loci in rice. Among these, 20 are major genes and 10 are assumed as quantitative trait loci. Twelve major genes have been confirmed to be non-allelic and are officially registered with the rice genetics cooperative. According to recent studies, 101 blast-resistance genes and 350 QTLs covering almost all the chromosomes of rice lines have been identified (Ballini et al., 2008; Ghaley et al., 2012 ; Sharma et al., 2012).

According to Rajashekara et al.(2014)F2 population from a cross between the resistant variety Vanasurya and susceptible rice cultivar CO-39 showed a segregation of 3R:1S, which revealed that resistance to blast disease is governed by a single dominant gene. On the other hand, Philippi and Prabhu (1996), reported that the F1 and F2 progenies of all crosses from resistant by susceptible lines showed resistance to be controlled by one to three genes that segregate independently in most donors, with non-allelic interaction among resistant genes, including dominant epistasis.

\section{Summery and conclusion}

Rice blast (Magnaporthe grisea) is an economical important disease which causes a devastating yield reduction and complete plant loss especially in upland rice producing areas of the world. It disseminates by wind, infected plant debris or seeds left in the field. The disease has different names in different areas as rice blast fungus, rice rotten neck, rice seedling blight, blast of rice, oval leaf spot of graminea, pitting disease, ryegrass blast, and Johnson spot. Disease symptoms can be found on all the above ground parts of the rice plant at all growth stages. The disease severity or the number of spores produced on a single lesion depends on temperature, field conditions, relative humidity, fertilization levels, and genotype of the cultivar. The fungus can propagate either sexually or asexually.

Developing resistant cultivars is the most desirable means of managing blast, particularly for small scale farmers, though integrated disease management options are the best way to combat rice blast. In addition to using resistant variety, nutrient management like application of recommended nitrogen fertilizers and application of silicon fertilizers hinders the occurrence of the rice blast.

The rice plant responds differently for reducing the occurrence and damage of the disease as rapid, localized cell death, production of anti-microbial compounds, lignin formation, an oxidative burst and increased expression of genes related to pathogenesis. This response would be either the fungus is incapable causing 
sporulating lesions on the plant or the plant develop residual resistance that remains when complete resistance has been overcome by the pathogen.

\section{References}

Adams, M., Bryan, H., Hershay, P., Valent, B., Jia, S., 2000. Direct interaction of resistance genes products confers rice blast resistance. Embo. J. 19, 4004-4014.

Agrios, G.N., 2005. Plant Pathology (5th edition). Elsevier- Academic Press, San Diego, CA.

Balasubramanian, V., Sie, M., Hijmans, R.J., Otsuka, K., 2007. Increasing Rice Production in Sub-Saharan Africa: Challenges and Opportunities, Advances in Agronomy. Elsevier Masson SAS.

Ballini, E., Morel, J.B., Droc, G., Price, A., Courtois, B., J.L. Tharreau, D.N., 2008. A genome-wide metaanalysis of rice blast resistance genes and quantitative trait loci provides new insights into partial and complete resistance; Mol. Plant Microb. Interact. 21, 859-868.

Bonman JM., 1992. Durable resistance to rice blast disease - environmental influences. Euphytica 63, 115-123.

Bussaban, B., Lumyong, S., Lumyong, P., Seelanan, T., Park, D.C., McKenzie, E.H.C., Hyde, K.D., 2005. Molecular and morphological characterization of Pyricularia and allied genera. Mycologia 97, 1002-1011.

Chuwa, C.J., Mabagala, R.B., Reuben, M.S.O.W., 2015. Assessment of Grain Yield Losses Caused by Rice Blast Disease in Major Rice Growing Areas in Tanzania 4, 2211-2218.

David, T., Claudia, G., Michael, D., 2012. Rice blast. Am. Phytol. Soc. 10, 1094.

Dounia, S., 2013. South-East Asia is the center of origin, diversity and dispersion of the rice blast fungus, Magnaporthe oryzae. New Phytol. 201.

Ghaley, B.B., Christiansen, J.L., Andersen, S.B., 2012. Genetic diversity for blast resistance of Bhutan rice landraces. Euphytica 184, 119-130.

Kato, H., 2001. Rice Blast Control. Rice Blast Disease. R. Soc. Chem.

Koga, Nakayachi, 2004. Morphological studies on attachment of Magnaporthe grisea to leaf surface of rice. J. Gen. Plant Pathol. 70, 11-15.

Hajano, J., Pathan, M., Rajput, Q., Lodhi, M., 2011b. Rice blast-mycoflora, symptomatology and pathogenicity. Int. J. Agro Vet. Med. Sci. 5, 53. doi:10.5455/ijavms.20110226124750

Hirsch, J., Balzergue, S., Tharreau, D., Notte, J., Lebrun, M., Morel, J., 2008. Susceptibility of rice to the blast fungus , Magnaporthe grisea 165, $114-124$.

Hori, S., 1898. Blast Disease of rice plants. Tokyo.

Iwata, M., 2001. Rice Blast Control. R. Soc. Chem. 3-5.

Jia, Y., Lee, F.., McClung, A., 2009. Determination of resistance spectra of the Pi-ta and Pi-k genes to U.S. races of Magnaporthe oryzae causing rice blast in a recombinant inbred line population. Plant Dis. 639-644.

Jin, X., Lee, E., Choi, J., 2010. Classification of Korean Rice Cultivars based on Reaction Pattern to Japanese Isolates of Blast Pathogen. J.Crop SCi. Biotech 10, 5-9.

Kayeke, J.M., Mghogho, Mwalyego, S., 2011. Important disease in rice production-symptoms, damage and management. Livelihood improvement through integrated management practices for rain fed lowland rice. ASARECA-RICE PROJECT, Mbeya,Tanzania.

Kiyosawa, S., 1967. Genetic studies on host-pathogen relationship in the rice blast disease. rice disease and their control by growing

Lee, E.J., Kim, H.K., Ryn, J.D., 1976. Studies on the resistance of rice varieties to the blast fungus, Pyricularia oryzae Cav. Korean.

Lule, D., de Villiers, S., Fetene, M., Bogale, T., Alemu, T., Geremew, G., Gashaw, G., Tesfaye, K., 2014. Pathogenicity and yield loss assessment caused by Magnaporthe oryzae isolates in cultivated and wild relatives of finger millet ( Eleusine coracana ). Indian J. Agric. Res. 48, 258.

Mekwatanakarn, P., Kositratana, W., Phromraksa, T., Zeigler, R.S., 1999. Sexually Fertile Magnaporthe grisea Rice Pathogens in Thailand. Plant Dis. 83, 939-943.

Miah, G., Rafii, M.Y., Ismail, M.R., Puteh, A.B., Rahim, H.A., Asfaliza, R., Latif, M.A., 2013. Blast resistance in rice: a review of conventional breeding to molecular approaches. Mol. Biol. Rep. 40, 2369-2388.

Miyake, K., Ikeda, M., 1932. Influence of silica application on rice blast. Japanese J. Soil Sci. Plant Nutr. 6, 5376.

Muriithi, C.W., Mugai, E.N., Kihurani, A.W., 2005. Effect of Nitrogen and Silicon on Management of Rice Blast (Pyricularia Oryzae) In Mwea Irrigation Scheme of Kenya 569-576.

Mohapatra, N.K., Mukherjee, a K., Rao, a V.S., Nayak, P., 2008. Disease Progress Curves in the Rice Blast Pathosystem Compared With the Logistic and Gompertz Models. ARPN J. Agric. Biol. Sci. 3, $28-37$.

Nutsugah, S.K., Twumasi, J.K., Chipili, J., Sere, Y., Sreenivasaprasad, S., 2008. Diversity of the Rice Blast Pathogen Populations in Ghana and Strategies for Resistance Management. Plant Pathol. J. 7, 109-113.

Padmanabhan, 1975. Inheritance of disease resistance in rice.

Padmavathi, G., Ram, T., Satyanarayana, K., Mishra, B., 2005. Identification of blast ( Magnaporthe grisea ) 
resistance genes in rice. Curr. Sci. 88, 628-630.

Park, J.-Y., Jin, J., Lee, Y.-W., Kang, S., Lee, Y.-H., 2009. Rice blast fungus (Magnaporthe oryzae) infects Arabidopsis via a mechanism distinct from that required for the infection of rice. Plant Physiol. 149, 474486.

Plank, V., Der, J.E., 1975. Horisontal resistanse six projects in relation to blast disease of rice. Horisontal resistanse to blast disease of rice. CIAT. Ser. CE 9.Call. Colomb. $21-26$.

Philippi, M.C. de, Prabhu, A.., 1996. Inheritance of blast resistance in rice to two Pyrincularia grisea races, IB-1 and IB-9. Brazilian J. jenetics 19, 599-604.

Prabhu, A., Morais, O., 1986. Blast disease management in upland rice in Brazil.

Preethi, G., 2005. Fungal Blast disease of Rice - Screening of Resistant gene Pik-h Fungal Blast disease of Rice Screening of Resistant gene Pik-h.

Pooja, K., Katoch, A., 2014. Past, present and future of rice blast management. Plant Sci. Today 1, $165-173$.

Rath, G., Padmanabhan, S.Y., 1976. Studies on inheritance of leaf blast resistance in rice. Proc. Indian Acad. Sci. 108-116.

Rajashekara, H., Ellur, R.K., Khanna, A., Nagarajan, M., Krishnan, S.G., 2014. Inheritance of blast resistance and its allelic relationship with five major R genes in a rice landrace "Vanasurya " 67, 365-369.

Richard, A., Wilson, Nicholas, J.T., 2009. Investigating the biology of plant infection by Magnaporthe oryzae. Nat. Rev. Microbiol. 7, 185-195.

Roumen, 1993. Partial resistance in rice to blast and how to select for it. Wageningen Agricultural University, Wagenin- gen, The Netherlands.

Sharma, T.R., Rai, A.K., Gupta, S.K., Vijayan, J., Devanna, B.., Ray, S., 2012. Rice Blast management through Host-Plant Resistance: Retrospect and Prospects. Agric. Res. 1, 37-52.

Sattari, A., Fakheri, B., Noroozi, M., 2014. Blast resistance in rice : a review of breeding and biotechnology 329-333.

Séré, Y., Fargette, D., Abo, M.E., Wydra, K., Bimerew, M., Onasanya, A., Akator, S.K., 2013. Managing the Major Diseases of Rice in Africa. Realiz. Africa's Rice Promise 213-228.

Séré, Y., Sreenivasaprasad, S., Nutsugah, S.K., 2005. Rice blast in West Africa : Characterisation of pathogen diversity, key screening sites and host resistance.

Stachowicz, J.J., Withlatch, R.B., 2005. Characterization of four rice mutants with alterations in the defence response pathway. Ecology 86, 2418-2427.

Talbot, N.J., 2003. Exploring the Biology of Magnaporthe grisea, On the Trail of a Cereal Killer. Annu. Rev. Microbiol. 57, 177-202.

Trinh, L., Khuyeu, D., Buu, B.C., 2008. Genetics and Breeding for Blast and Bacterial Leaf Blight Resistance of Rice (Oryza sativa. L) 49, 41-49.

Yang, D., Yang, Y., He, Z., 2013. Roles of Plant Hormones and Their Interplay in Rice Immunity. Mol. Plant 6, $675-685$.

Yang, H., Yang, X., C.M, L., Wang, Y., 2011. The correlation analysis between blast resistance and genetic diversity of 39 Yunnan glutinous rice varieties. J. Yunnan Agric. Univ. 26, 1-5.

Wang, X., Lee, S., Wang, J., Ma, J., Bianco, T., Jia, Y., 2014. Current Advances on Genetic Resistance to Rice Blast Disease. Rice- Germplasm, Genet. Improv. 1-28.

Wassmann, R., Jagadish, S.V.K., Heuer, S., Ismail, A., Redona, E., Serraj, R., Singh, R.K., Howell, G., Pathak, H., Sumfleth, K., 2009. Climate Change Affecting Rice Production. The Physiological and Agronomic Basis for Possible Adaptation Strategies, 1st ed, Advances in Agronomy.

Usman, G.M., Wakil, W., Sahi, S.T., Saleem, il. Y., 2009. Influence of various fungicides on the management of rice blast disease 7, 29-34.

Zarandi, M.E., Bonjar, G.S., Dehkaei, F.P., Moosavi, S.A., Farokhi, P.R., Aghighi, S., 2009. Biological Control of Rice Blast ( Magnaporthe oryzae ) by use of Streptomyces sindeneusis isolate 263 in Greenhouse. Am. J. Appl. Sci. 6, 194-199. 